IFN Working Paper No. 759, 2008

\title{
Renewal of Patents and Government Financing
}

Roger Svensson 


\title{
Renewal of Patents and Government Financing
}

\author{
Roger Svensson *
}

August 2008

Key words: Patents, Renewal, Government Financing, Survival Model

JEL Classification: O34, O38, G30

\begin{abstract}
I apply a survival model to a detailed dataset of Swedish patents to estimate how different factors affect the likelihood of patent renewal. Since the owners know more about the patents than potential external financiers, there is a problem of asymmetric information. To overcome this, Sweden has for a long time relied on government support rather than private venture capital. The empirical results show that patents which have received soft government financing in the R\&D-phase have a higher probability of expiring than patents without such financing. But patents that have received more market-oriented government loans during the commercialization phase are renewed for as long as other commercialized patents. This finding indicates that it is the financing terms rather than bad choices of projects that explain the low renewal of patents with government financing.
\end{abstract}

* Research Institute of Industrial Economics (IFN), P.O. Box 55665, SE-10215 Stockholm, Sweden; Email: roger.svensson@ifn.se ; Tel: + 46-8-665 405 49; Fax: + 46-8-665 4599.

The author would like to thank Per Botolf Maurseth, Ove Granstrand, Erik Mellander, Johan Almenberg and Magnus Henrekson and the seminar participants at SNEE conference in Mölle, Stockholm School of Economics and IFN for constructive comments, as well as Jakob Eliasson for collection of and work with the dataset. Financial support from the Torsten and Ragnar Söderberg's Foundation is gratefully acknowledged. This study was written within the Gustaf Douglas Research Program on Entrepreneurship. 


\section{Introduction}

Patents, and the inventions behind them, are crucial for economic growth. Previous studies have tried to estimate the distribution of private market values of patent rights through: 1) asking the patent owners directly about the market values (see, e.g. Rossman and Sanders, 1957; Schmookler, 1966); 2) relating the firms' profits or market values to patents or innovations (see, e.g. Griliches et al., 1987; Hall 1993); or 3) analyzing the renewal of patents (Pakes, 1986; Schankerman and Pakes, 1986). The last group of studies is based on the fact that the patent holders typically pay an annual fee to keep their patents in force. Rational owners will only renew their patents if it is economically profitable to keep them - an approach which is also used in this study. A drawback of previous patent renewal studies is that they seldom analyze how different strategies or explanatory factors influence the renewal decision. For example, it is not observed whether the patents are commercialized and, thus, whether innovations are introduced in the market, which should be important for the renewal decision. Patents may also be kept for strategic reasons, for example as defensive patents. Such patents deter competitors from using the invention or serve as shadow patents, i.e. protect other similar patents.

The purpose of the present study is to analyze how a number of different factors influence the decision to renew a patent. In the empirical analysis, I use a unique dataset on Swedish patents granted to individuals and small firms. The dataset contains detailed information about individual patents, such as, firm type, whether the patents were commercialized and/or renewed, financing and the number of patent citations. I use a survival model to test empirically how these different explanatory factors affect the renewal decision. Such a survival analysis including explanatory variables has rarely been undertaken in the study of patents. ${ }^{1}$

The specific purpose is to analyze how different financing alternatives influence the renewal decision. In the previous literature, external financing has empirically been shown to be important for patenting (e.g., Kortum and Lerner, 2000) and commercialization of patents (Svensson, 2007). However, external financing has not been empirically related to the renewal decision. External financing is important when small firms and individuals wish to introduce innovations on the market. Since inventors and owners have more knowledge about the patent compared to potential

\footnotetext{
${ }^{1}$ An exception is Maurseth (2005).
} 
external financiers, problems related to adverse selection and moral hazard are present. To overcome these problems and thereby aid economic growth and job creation, the Swedish government has provided financial assistance and loans to inventors and small technology-based firms. In the R\&D-phase, grants and loans with soft terms are offered. The loans are written off with a very high probability if: 1) the patent is never commercialized; or 2) the commercialization fails. Such terms create moral hazard problems, because there are few incentives for patent owners to continue with commercialization or keep the patents. In the commercialization phase, the government loans are more market-oriented. By including different terms of government financing in the model, I am able to examine if these terms can explain differences in the renewal pattern.

The paper is organized as follows. Previous studies about renewal of patents and adequate theories are discussed in section 2. The theoretical and statistical models are specified in section 3 . The dataset and explanatory variables are described in section 4 . The empirical results are shown in section 5. The final section concludes.

\section{Previous studies and theoretical discussion}

\subsection{Previous patent renewal studies}

Patent owners must pay a annual renewal fee to keep their patents in force. Griliches (1990) points out that owners should only renew their patents if it is economically profitable to do so. The fraction of patents that are renewed is then an indication of how large a share of the patents that have an economic value after a given number of years. Schankerman and Pakes (1986) assume that more valuable patents are renewed for a longer time, and estimate both the distribution of the patent values and their rate of depreciation. They show that about half of European patents are still renewed after 10 years, but only 10 percent are renewed for the whole statutory period. According to Griliches (1990), most patents have a low value and depreciate fast, and only a few patents have a significant high value.

The renewal decision has seldom been related to explanatory factors. Duguet and Iung (1997) use patent renewal data on firm level, which is related to factors as R\&D intensity and firm size. They conclude that the renewal decision is positively related to product imitations on the industry level. Harhoff et al. (1999) show that German and U.S. patents that are renewed for the whole statutory period receive more 
citations than expired patents. They conclude that there is a positive correlation between patent value and the number of citations a patent receives. Maurseth (2005) uses a survival model to explain the renewal pattern, but makes a distinction between citations across and within technology fields. He finds that patents which receive citations across fields survive longer, whereas patents with citations within the same field expire earlier. The interpretation is that citations across technology fields indicate a scientific breakthrough, while citations within fields indicate many competing innovations. These hypotheses with how patent citations are related to patent renewal will also be tested in the present study.

\subsection{Government financing}

Patents are typically characterized by high costs and no revenue in the early R\&Dphase, and by high uncertainty about future revenues. Besides technological problems, lack of financial resources is one of the largest problems during the R\&D-phase. In the subsequent commercialization phase, several complementary resources are needed, e.g., financing, marketing and manufacturing capabilities. Large firms have these complementary capabilities as well as information about the market. Small firms have these resources in-house to a lower degree and individuals even less so. Thus, the conditions under which inventions are commercialized may differ considerably between large firms, small firms and individuals. External financing and advice are likely to be needed by individuals in particular, and to some extent also by small firms.

Inventors have more knowledge about the patent (and the underlying invention) than potential external financiers. This implies problems of asymmetric information and adverse selection. Consequently, search and transaction costs incurred when finding interesting projects and evaluating their commercial potential are large for external financiers. It is especially difficult to make this evaluation in the R\&D-phase, when uncertainty about the project is very high. Therefore, market imperfections are likely to exist on the market for financing of innovation projects (Kaplan and Strömberg, 2001).

To overcome market failures and the gap between inventors and external financiers, different countries have applied different strategies (Braunerhjelm, 1999, and Bottazzi et al., 2004). In the United States, the government has facilitated private market solutions and the growth of private venture capital firms (Gompers and Lerner 2001). In Sweden, the government has intervened by offering financial assistance and loans to inventors and small technology-based firms. 
Numerous studies show that R\&D is important for economic growth and that the social return from business $R \& D$ is higher than the private return. The latter fact justifies government R\&D support programs to inventors and firms carrying out R\&D. Guellec and van Pottelsberghe (2004) estimate that business R\&D generates spillover effects and increases the firms' ability to absorb external technology. Governments in many countries have programs aimed at supporting $R \& D$, but also aimed at supporting entrepreneurial activity and the creation and growth of start-up firms in general. These programs are typically promoted as a means to create jobs and stimulate economic growth. According to Kirzner (1985), these support programs can be divided into two kinds: (1) reducing the private cost of $R \& D$ and entrepreneurial activity; and (2) stimulating people to become entrepreneurs through teaching and encouragement. Programs of the first kind mostly involve some kind of financial support to remove barriers to business formation. This kind of program is based on the assumption that financial markets disfavor small firms and entrepreneurs.

Although these government support programs are common, they are seldom evaluated. Thus, little is known about their efficiency. One strand of the evaluation studies has analyzed the effects on the macroeconomic level. For example, Lichtenberg (1993) estimated that government-funded R\&D performed by firms is less efficient than business-funded R\&D. However, Guellec and van Pottelsberghe (2003) show that government funding - both direct funding and tax incentives - of R\&D performed by firms has a positive impact on business R\&D. They conclude that the negative relationship only holds for defense-related R\&D. Another group of studies has estimated the effects on the firms' performance. For example, Maggioni et al. (1999) test the efficiency of government financial aid to technology-based start-up firms in Italy. They concluded that the program increased the number of high technology startup firms, but that these firms were somewhat inefficient. Aided firms had a higher financial risk and did not grow more than non-aided firms. ${ }^{2}$

Tthe Swedish Government offers financial assistance and loans with soft terms to inventors and small technology-based firms in the early R\&D phase (i.e. before manufacturing has started). The borrower pays a subsidized interest rate and begins to pay back the loan some years after the commercialization has started. However, if there

\footnotetext{
${ }^{2}$ The authors explain this inefficiency by that easy access to initial resources: 1) does not take account of high uncertainty faced by new ventures; and 2) reduces the entrepreneurial skills, since the development of such skills is not favored.
} 
is no commercialization or if commercialization is attempted but fails, there is a high probability that the borrower need not pay back the loan at all. A requirement for debt forgiveness from the government agency is that the patent has to expire. If the borrower does receive incomes during commercialization, the repayment of the loan is connected to product turnover.

The soft loans offered by the Swedish government authorities in the 1990s are described in detail in the Appendix. To give soft loans to a firm or an inventor in the R\&D phase, the government authorities have had two selection criteria: 1) the project should have a good chance of success both technically and commercially; and 2) the project is a high-tech project. Government financing could cover up to 50-70 percent of the total R\&D costs depending on which government authority provided the loan. Thus, there was a requirement of co-financing by the borrower or somebody else, but this financing was allowed to take the form of unpaid labor incomes. This is a cost that cannot be controlled by the government authority (raising moral hazard problems). In practice, the government loans could therefore cover more than 80 percent of the project's total $R \& D$ costs.

Loan terms where repayment is connected to turnover rather than profit imply that projects with a low or medium expected profit level would probably not be commercialized at all, since the repayment of the loan would then erase the whole profit. However, this will not prevent commercialization if the expected profit level is high. Due to the design of the loans from government institutions, problems related to moral hazard are likely to emerge. Inventors who have received soft loans from the government need not care about further commercialization of the patent, since they know that it is likely that they will not have to pay back the loans at all. It is often better to exit the project, receive debt forgiveness the and move to a new project. Last but not least, the loans are given to the project. This implies that the borrower can close down the project, let the patent expire and use what he/she has learnt in a new project.

The government also provides loans during the commercialization phase. These loams are usually on terms that are more similar to commercial loans. The loan is connected to the firm. Accordingly, the firm can only avoid repayment if it goes into bankruptcy. Repayment is not connected to the turnover. These loans have an interest rate close to the one charged by banks. The terms of these loans do not reduce the borrower's incentives to make the innovation perform well in the market. 
Financing during the R\&D-phase can be supplied by private venture capital (PVC) firms or individuals (so called "business angels") in return for shares in the patent project. Repayment is then connected to whatever profit may arise when the patent is commercialized. In contrast to government-financed projects, this means that even if the expected profit is mediocre, the inventors have incentives to undertake commercialization.

Furthermore, government-financing institutions typically do not maximize their profit. Therefore, their administrators have few incentives to search for really good patent projects to which they lend money. The employees do not invest their own private money. On the other hand, PVC firms and business angels aim more consistently at profit-maximizing. They are more likely to be careful than government institutions about the patent projects they choose to invest in, and should have a more active role already during the R\&D phase. PVC firms not only provide financial capital, but also networks and competence in terms of knowledge about, for example, market conditions, marketing, juridical assistance (Bottazzi et al., 2004; Hellmann and Puri, 2002). An inventor or a firm that has received contacts and financing from a PVC firm or a business angel in the R\&D phase should more easily receive financing and advice during the commercialization phase. Thus, bad performance of projects with government funding might depend on government administrators not being able to select promising projects to fund.

In Svensson (2007), empirical estimations show that patent owners who receive soft government loans are less likely to commercialize their patents. However, since only one kind of government loans is analyzed, there is no room to discriminate between moral hazard (bad loan terms) and adverse selection (bad selection of projects) as explanations for why some patents perform badly. In the present study, both soft loans given in the R\&D-phase and more market-oriented loans given in the commercialization phase are related to the renewal decision of patents.

A common opinion is that the government selects among projects that have been turned down by private investors. Therefore, loans from the government would go to relatively less profitable or more risky projects. However, Kaivanto and Stoneman (2006) have shown that specific, soft government loans, as described above, are more attractive for inventors, and have a higher pecking order, than equity financing from 
private venture capitalists. ${ }^{3}$ Thus, it is not necessary the case that the government chooses among inferior projects that have been turned down by private investors. The authors give three reasons why such soft loans are attractive for firms and inventors. First, the patent owners do not lose control of the project. Second, the repayment is a variable cost, not a fixed cost, and does not increase the financial risk of the firm. Third, debt usually requires collateral financing. However, the soft government loans are backed by future incomes and therefore do not require any collateral.

\section{Theoretical and statistical models}

\subsection{Theoretical model}

The model described here follows Schankerman (1998). Since Swedish patents can only expire at fixed annual dates, I use discrete time. ${ }^{4}$ The patent owner must pay an annual renewal fee, $C_{a j}$, to keep the patent in force. This fee varies with age $a$ and cohort $j$ of the patent. ${ }^{5}$ The patent owner who pays the renewal fee earns the current implicit return to patent protection during the coming year, $R_{a j}$. It is assumed that the pattern of $R_{a j}$ is known with certainty when the patent is applied for. If the owner does not pay the fee, the patent expires permanently and the return is equal to zero thereafter. The owner's decision problem is then to maximize the discounted value of net returns by choosing the age at which to stop paying the renewal fee. Therefore, the owner chooses a lifetime, $T$, in order to solve the problem:

$$
V(T)=\max _{T \leq M} \sum_{a=1}^{T} r^{a}\left(R_{a j}-C_{a j}\right)
$$

where $V$ is the value of patent protection given the optimal renewal decision, $r$ is the discount rate and $M$ is the statutory limit of patent protection (20 years). Provided that the path of net revenues $\left(R_{a j}-C_{a j}\right)$ is non-increasing in age, the optimal rule for the owner is to renew the patent as long as the revenues cover the renewal costs, i.e. as long as $R_{a j} \geq C_{a j} .^{6}$ When the net returns become negative, the owner should stop payment. If no such time point exists, the patent should be kept for the maximum life span $(T=M)$.

\footnotetext{
${ }^{3}$ The authors call this kind of government financing "sales contingent claims" (SCC), which are almost identical to the soft loans provided by the Swedish government.

${ }^{4}$ Maurseth (2005) uses a model with continuous time, similar to that with discrete time.

${ }^{5}$ All patents applied for in the same year belong to the same cohort.

${ }^{6}$ The renewal fees are non-decreasing in age. A sufficient condition for the net revenues to be nonincreasing in age is that the path of revenues, $R_{a j}$, is non-increasing in age.
} 
Thus, the renewal decision is an optimal stopping problem and the patents can be seen as options. The initial returns in a given cohort, $R_{0 j}$, are allowed to vary across patents, but are assumed to decay by the same rate, $\delta_{a j}$. If all patents in a cohort had the same initial returns and path of revenues, they would all expire at the same age. If $R_{a j}=$ $R_{0 j} e^{x \beta} \prod_{t=1}^{a} d_{t j}$ and $d_{t j}=\left(1-\delta_{t j}\right)$, the condition for renewal of patent $i$ at age $a$ can be written:

$$
R_{i 0 j} \geq C_{a j} e^{-x_{i} \beta} \prod_{t=1}^{a} d_{t j}^{-1}
$$

where $\mathbf{x}$ is a vector of patent-specific explanatory variables and $\boldsymbol{\beta}$ is a vector of parameters. Let $g\left(R_{0 j} ; \boldsymbol{\theta}\right)$ and $G\left(R_{0 j} ; \boldsymbol{\theta}\right)$ be the density and cumulative distribution functions of initial returns, where $\boldsymbol{\theta}$ is a vector of parameters. The proportion of patents in cohort $j$ renewed at age $a$ is:

$$
P_{a j}=\int_{z_{a j}}^{\infty} g\left(R_{0 j} ; \theta\right) d g=1-G\left(z_{a j} ; \theta\right)
$$

where $z_{a j}=C_{a j} e^{-x \beta} \prod_{t=1}^{a} d_{t j}{ }^{-1}$. Given a functional form of $R_{0}$, equation 3 provides the basis for the relationship between patent renewal and the unknown parameters. Since $P_{a j}$ is a function of $t$, equation (3) is in fact the survival function of patents, $S(t)$, which shows the probability of a patent surviving beyond time point $t$. The cumulative distribution function of patent duration is given by $F(t)=1-S(t)$.

One objection against the model is that $R_{a j}$, the net return from a patent, is uncertain. There may also be an uncertainty about the market conditions, which might affect the renewal decision. These uncertainties are discussed by Maurseth (2005), but have neither been applied in the previous studies that rely on semi-parametric or parametric models nor in the present study.

\subsection{Statistical model}

Since the analysis focuses on an event to occur, survival (duration) analysis is used in the statistical estimations. The event in question is the decision to let the patent expire,. I begin by estimating a survival distribution function and a hazard function. The survival function, $S(t)$ in equation 1 , shows how a large share of the patents survive beyond a time point, $t$. The hazard function, $h(t)$ in equation 2 , shows the conditional probability of a patent expiring in a specific time period $\Delta t$, given that it has been 
renewed until time point $t$. The hazard can also be expressed as a function of the probability density function, $f(t)$, and the survival function:

$$
\begin{aligned}
& S(t)=\operatorname{Pr}(T>t)=1-F(t), \\
& h(t)=\frac{f(t)}{S(t)}=\lim _{\Delta t \rightarrow 0} \frac{\operatorname{Pr}(t \leq T<t+\Delta t \mid T \geq t)}{\Delta t} .
\end{aligned}
$$

In the main empirical analysis, I estimate how different explanatory factors affect the decision to let the patents expire. The dependent variable, $t_{i}$, is a random variable showing how many years it takes until patent $i$ expires, measured from the time point of patent application. ${ }^{7}$ Patents that have not yet expired in 2004 - the end point of observation - are "right-censored" (480 observations). The other 387 patents have expired in 2004 at the latest. Given this, the appropriate statistical model is the Cox (1972) proportional hazard model:

$$
\log h_{i}(t)=\log \lambda_{0}(t)+x_{i 1} \beta+x_{i 2}(t) \gamma
$$

where $\log \lambda_{0}(t)$ is a baseline hazard function, $\boldsymbol{\beta}$ and $\boldsymbol{\gamma}$ are vectors of parameters to be estimated, $\mathbf{x}_{\mathbf{1}}$ is a vector of time independent explanatory variables, and $\mathbf{x}_{\mathbf{2}}(\mathbf{t})$ is a vector of time dependent explanatory variables. The measurement of number of years is an exact measure, since the owner must pay a renewal fee the same date every year as the patent was applied for. Therefore, I use a discrete approximation of the Cox model, to account for the fact that two or more events may occur at the same point in time (Allison, 1995).

A patent cannot expire until it has been granted, and is therefore not in the risk set before this time point. If the owner had not paid the renewal fee for an applied patent before the patent was granted, the invention would neither have been granted a patent nor have been included in the dataset. Therefore, I remove the patent from the risk set between the origin (application date) and the time point for granting patents. ${ }^{8}$ This is an

\footnotetext{
${ }^{7}$ The application year is the standard starting time point to use. Information on the application year is directly available from the Swedish National Patent Office (PRV).

${ }^{8}$ This procedure is called left truncation. It is accomplished by defining a time-dependent covariate whose values are missing at times when the patent is not in the risk set. In practice, this means that patents, which have a grant date before the renewal (application) date in 1998, will get a starting year of 1997 (the first possible year of expiration is then 1998). If the renewal date occurs before the grant date in 1998, the starting year is 1998 (the first possible year of expiration is then 1999).
} 
important methodological extension beyond previous studies, which do not take this into account. ${ }^{9}$

The largest advantage with the Cox model compared to the alternative statistical model, the accelerated failure time model, is that time dependent explanatory variables can be included in the estimations. In the present study, the time point of commercialization of the patent will be included. Another advantage of the Cox model is that there is no need to choose between different residual distributions. Thus, the baseline hazard function, $\log \lambda_{0}(t)$, can be left unspecified. Finally, the Cox model makes it possible to interpret the quantitative effects in terms of how an increase in the explanatory variable affects the hazard.

Maurseth (2005) also estimates a log-likelihood model to test how the explanatory variables influence the expected survival time (see equations 12-13 and Table V in Maurseth, 2005). ${ }^{10}$ This type of parametric model is not able, however, to handle time-dependent explanatory variables. Since time-dependent variables are essential in the present model, I cannot estimate the model used in Maurseth (2005). It is beyond the scope of the present paper to estimate a distribution of patent values, along the same lines as e.g. Schankerman (1998). I do this in a separate study.

\section{Dataset and descriptive statistics}

I use a unique data set on patents granted to small firms (less than 1000 employees) and individual inventors. ${ }^{11}$ The dataset is based on a survey of Swedish patents granted in 1998. In that year, 1082 patents were granted to Swedish small firms and individuals. ${ }^{12}$ The sample selection is not a problem, as long as the conclusions are drawn for small

\footnotetext{
${ }^{9}$ Using the grant year as the starting year in the model is not appropriate, since some of the timedependent explanatory variables (in particular, those associated with the commercialization decision) change values between the application and the grant dates.

${ }^{10}$ Maurseth (2005) estimates the decay rate, as well as the mean and the standard deviation of patent returns, $R_{a j}$ in order to estimate the distribution of patent values. This is similar to previous studies in this area (see, e.g. Schankerman, 1998). The estimated parameters are then used to estimate how explanatory variables influence the time it takes until patents expire.

${ }^{11}$ All inventions do not result in patents. However, since an invention that does not result in a patent is not registered anywhere, there are two problems in empirically analyzing the invention rather than the patent. First, it is impossible to find these new ideas, products and developments among all firms and individuals. On the other hand, all patents are registered. Second, even if the inventions are found, it is difficult to judge whether they are sufficient improvements to qualify as inventions. Only the national and international patent offices make such judgements. Therefore, focusing on patents rather than all inventions is the only alternative for an empirical study of the commercialization process.

${ }^{12}$ In 1998, 2760 patents were granted in Sweden. 776 of these were granted to foreign firms, 902 to large Swedish firms with more than 1000 employees, and 1082 to Swedish individuals or firms with less than 1000 employees. In a pilot survey carried out in 2002, large Swedish firms refused to provide information on individual patents. Furthermore, it proved very difficult to persuade foreign firms to fill in questionnaires about patents. These firms are almost always large multinational firms.
} 
firms and individuals. Information about inventors, applying firms and their addresses as well as application dates and renewal dates for each patent was acquired from the Swedish Patent and Registration Office (PRV). Using this information, a questionnaire was sent out to the inventors of the patents. ${ }^{13}$

In the questionnaire, inventors wee asked about the work place where the invention was created and the financing of the invention during the R\&D-phase. They were also asked if and when the invention had been commercialized, how the commercialization was financed, and whether the commercialization was profitable. 867 of the 1082 inventors filled in and returned the questionnaire, i.e., the response rate was 80 percent. This response rate is satisfactorily high, if taking into account that such a dataset has seldom been collected before and that inventors or applying firms usually consider information about inventions and patents to be secret.

In Sweden, patent owners must pay an annual renewal fee to the national patent office to keep their patents in force. If the renewal fee is not paid in any single year, the patent expires. A patent can only expire at a fixed date every year, which coincides with the application date. In 1999, the size of the renewal fees was increasing annually ranging from 200 SEK in the first year to 4,300 SEK in the last year, adding up to total of around 35000 SEK over 20 years. ${ }^{14}$ The Swedish renewal fees are modest in size compared to the fees for European (EPO) and American patents (Van Pottelsberghe de la Potterie and Francois (2006). ${ }^{15}$

The commercialization and renewal rates of the 867 patents by firm size are described in Table 1. 408 patents (47 percent of the sample) were granted to individuals, and 116, 201 and 142 patents were granted to medium-sized firms (101-1000 employees), small firms (11-100 employees) and micro companies (2-10 employees),

\footnotetext{
${ }^{13}$ Each patent always has at least one inventor and often also an applying firm. The inventors or the applying firm can be the owner of the patent, but the inventors can also own the patent indirectly, via the applying firm. Sometimes, the inventors are only employed in the applying firm, which owns the patent. If the patent had more than one inventor, the questionnaire was sent to one inventor only.

${ }^{14}$ In 1999, the annual fees for the 20 years in ascending order were: $200,250,350,550,700,900,1100$, 1350, 1 600, 1 900, 2 250, 2 500, 2 700, 2850,3 050, 3 300, 3 550, 3800,4050 and 4300 SEK.

${ }^{15}$ According to Van Pottelsberghe and Francois (2006), the total cost for a patent which is renewed for 20 years is EUR 120000 (40 000) in 13 (3) EPO member states, EUR 14500 in the U.S. and EUR 17300 in Japan. High costs include procedural costs (official costs up to the grant date) and external services that the inventor/firm needs when filing the patent. The high cost of an EPO patent is due to high translation costs. The granted patent must be translated and validated in each targeted national patent office. The other reason why EPO patents are more expensive is higher annual renewal fees (which vary with the duration of the protection). The authors show that renewal fees for 20 years in the EPO system are EUR 89000 (22 000) in 13 (3) member states, whereas this cost is considerably lower in the U.S. and Japan. However, the renewal fees in a single European country like Sweden are of modest size.
} 
respectively. ${ }^{16}$ The commercialization rate for the whole sample is 61 percent. This rate should be compared to the few available studies which have measured commercialization of patents in other contexts: 47 percent for American patents reported by Morgan et al. (2001) and 55 percent in the American studies surveyed by Griliches (1990). ${ }^{17}$ The higher commercialization rate in the present study is most likely explained by the fact that only patents owned by small firms and individual inventors are included. Large (multinational) firms tend to have many more defensive patents. Griliches (1990) reports a commercialization rate of 71 percent for small firms and inventors, confirming this view.

In the current sample, the commercialization rate for patents held by firms ranges from 66 to 74 percent as compared to the rate of 51 percent for individual patent holders. A contingent-table test indicates a statistically significant difference between the commercialization rates of firms and individuals. The chi-square value is 30.6 (with 3 d.f.), significant at the one percent level.

The renewal rate is increasing in the firm size, rising from 44 percent for individuals to 76 percent for medium-sized firms. A contingent table test indicates a statistically significant difference between firm size categories. The chi-square value is 46.7 (with 3 d.f.), significant at the one percent level.

[Table 1]

The renewal rate is related to external financing in the $R \& D$ phase in Table 2. Patents with external financing in the R\&D-phase have a significantly lower renewal rate than those without. When dividing the external financing on different sources, the renewal rate is significantly lower only for patents supported by government funds. ${ }^{18}$ However, it is not shown when the patents expired. Such a survival analysis will be

\footnotetext{
${ }^{16}$ The group of individual inventors includes private persons, self-employed inventors as well as groups of two to four inventors, who are organized in trading companies or private firms without employees.

${ }^{17}$ These studies use a definition of commercialization that is similar to mine, i.e. that the patent has been used commercially. In Morgan et al. (2001) commercialization means a commercialized product or process or a licensing contract, in Griliches (1990), it means that the patent is used commercially. The commercialization does not need to be profitable for the owner in either of these studies.

${ }^{18}$ In the group with other external financing (universities, research foundations), the financing might be from a government agency or a private source, but the intention with this kind of financing is not to finance a patent application/project, but rather research in general. Here, inventors often use the resources for the patent without the financers' (mostly a university) knowledge. Therefore, this kind of financing is regarded as passive. In contrast, the government and private groups represent active financing, where the financier supports, or invests in, a specific patent.
} 
undertaken in the statistical part. It should also be noted that external financing irrespective of source - is more common among individuals and close companies. Of the 142 government-financed projects, 111 can be found among individuals and 25 among close companies. The risk should be higher in patent projects owned by individuals as compared to projects owned by companies. It would then be expected that the government finances projects with higher risk than the average patent project. This might be an explanation for the lower renewal rate among government-financed projects. However, in the group of 408 patents owned by individuals, the renewal rate is $30 \%$ for government-financed projects and 49 percent for projects with no government financing.

[Table 2]

Table 3 compares commercialized patents and renewed patents. As expected, renewed patents (71 percent) are commercialized to a higher degree than expired ones (48 percent). The chi-square test statistic reported at the bottom of Table 3 shows that we can clearly reject independence of commercialization and renewal. However, 35 percent of the patents have been commercialized, but have already expired. This is either due to the products having a short lifecycle or the commercialization having failed. 42 percent of the non-commercialized patents are still alive. Many of these patents might be defensive patents, with the purpose of defending other patents, but then the owner should have more similar granted patents. Among the commercialized patents in our dataset, 46 percent of the owners have at least one more similar patent. Among the non-commercialized patents, this percentage is only 33 percent. If the patent had not been commercialized, the inventor was also asked: why the patent had not been commercialized. Among the 341 non-commercialized patents, only 15 inventors listed shadow-patenting as one of the reasons for why the patent had not been commercialized. ${ }^{19}$ This indicates that keeping patents for strategic reasons, as is frequently done by large multinational firms (Cohen et al., 2000), is uncommon among individuals and small firms.

\footnotetext{
${ }^{19}$ The most frequent reasons here were: 1) problems with financing (115 patents); 2) problems with marketing (75 patents); 3 ) problems in finding a manufacturing firm/licensor (74 patents); and 4) the product is not yet ready for commercialization (62 patents). Note that inventors may have mentioned more than one reason for why the patent was not commercialized.
} 
[Table 3]

\section{Explanatory variables and hypotheses}

The explanatory variables consist of factors that are expected to affect, or to be correlated with, the probability that the patent will be renewed or expire. Patents that are commercialized or used for defensive purposes are expected to survive for longer periods. $^{20}$ Table 4 reports basic statistics for the explanatory factors. Hypotheses are shown for the main variables only. A positive (negative) expected parameter estimate means that the hazard rate of letting the patent expire increases (decreases), when the explanatory variable obtains a higher value.

[Table 4]

\subsection{Commercialization and defensive purposes}

The most obvious explanatory variable is whether the patent is commercialized or not. This factor can only be included as a time-dependent covariate. The commercialization decision is represented by an additive dummy, COM, which takes on the value 1 once the commercialization has begun, and 0 otherwise. The expected impact on the hazard is negative.

Keeping a patent for defensive purposes is the second main explanatory factor for the renewal decision, besides commercialization. If the patent is not commercialized but kept as a shadow patent to protect other closely related patents, the additive dummy $D E F$ equals 1 and 0 otherwise. The expected impact on the hazard is negative. The fact that only non-commercialized patents can take on the value of 1 for $D E F$ is important for the interpretation of the parameter estimates for this variable as well as COM. The parameter estimate for $D E F$ will show the difference as compared to other noncommercialized patents, since a patent cannot take on the value of 1 for both $D E F$ and $C O M$. By the same reason, COM shows the difference as compared to noncommercialized patents, which are not shadow-patents.

\footnotetext{
${ }^{20}$ Commercialization and defensive purposes are the two main reasons why inventors choose to patent their inventions at all (Griliches, 1990).
} 


\subsection{Financing variables}

As discussed above, Swedish government agencies assist in the financing of patent projects in the R\&D phase. These loans have a rather particular design. The borrower receives debt forgiveness if the patent is not commercialized, or if the project fails. Therefore, it is likely that the government financing during the R\&D phase generates moral hazard problems, which in turn suggests that patents with such financing will expire with a higher relative frequency. The dummy variable GOVRD equals 1 if part of the R\&D-phase was financed through government grants or soft loans, and 0 otherwise. ${ }^{21}$ A positive influence on the hazard is expected.

In section 2, it was mentioned that the government especially offers loans to projects owned by individual inventors. Such projects should have a higher risk than projects run by companies. To take account of the higher risk associated with patents owned by individuals, an interaction dummy, $D$, taking the value of 1 if the patent is owned by a firm, and 0 otherwise, is used for GOVRD. ${ }^{22}$ In practice, the parameter of GOVRD, $\alpha_{G F}$, is divided into two parts:

$$
\alpha_{G F}=\alpha_{\text {Ind }}+\alpha_{D} D
$$

$\alpha_{\text {Ind }}$ shows the parameter value of GOVRD for the group of individual s, $\alpha_{\text {Ind }}+\alpha_{D}$ is the parameter value for the firm groups and $\alpha_{D}$ shows whether there is a significant difference for the parameter of GOVRD between firms and individuals.

In a similar way, the dummy variable $P R I V R D$ equals 1 if the $R \& D$-costs were financed (at least partially) through external private venture capital and 0 otherwise. Unlike the government agencies, the private venture capitalists are assumed to be strictly profit maximizing. They only invest in projects they believe to be profitable. External financiers should therefore push harder for patents to be commercialized and create incomes. It is also likely that patents with external private financing during the $R \& D$ phase also find it easier to attract external venture capital (from the same private venture capitalists) during the commercialization phase. Therefore, a negative effect of PRIVRD on the hazard is expected.

\footnotetext{
${ }^{21}$ Patent application costs are included in the R\&D costs.

${ }^{22}$ Preferably, three different interaction dummies would be included - one for each firm group. However, there are only three patents with government financing in each of the groups of medium-sized and small firms. When estimating the model with three interaction dummies, the small variation with respect to government financing in these two groups causes extremely high values of the standard errors of two of the interaction dummy parameters. Therefore, the three firm groups must be pooled into one group.
} 
There is also a third kind of external financing. This is captured by the dummy variable OTHERFIN that takes on the value of 1 if a project was financed through universities or research foundations during the R\&D phase and 0 otherwise. Typically, patents created at universities have this kind of external financing, the purpose of which is not to assist a patent project, but rather to finance $R \& D$ in general. The financers seldom have any control of for what the resources actually are used. It is difficult for inventors to use the resources for patent applications, but easier to hide the labor costs necessary for creating the invention within this financing. A problem with this kind of financing is that it cannot be used for commercialization. Consequently, inventors may find themselves without financing when considering commercialization. A positive parameter estimate is therefore expected.

Financing from the government or private venture capital firms during the commercialization can only be given to commercialized patents. Therefore, interaction dummies must be created. The dummy GOV takes on the value of 1 if the project received government financing during the commercialization and $P V C$ equals 1 if the project received private venture capital during the commercialization phase and 0 otherwise. These dummies are then multiplied by COM, creating the variables GOVCOM and PVCCOM. The parameter of GOVCOM will then show whether the patents which have received government financing during the commercialization survive longer than other commercialized patents. The impacts of GOVCOM and PVCCOM on the hazard are unsettled,

Based on the terms of government financing and the length of patent renewal, two mutually exclusive hypotheses are set up, which is possible since two kinds of government financing are included in the analysis:

Hypothesis A: If patents with soft government financing expire faster than patents without such financing, but projects with market-oriented government financing do not expire faster than other commercialized patents, then the failure should depend on bad government loan terms.

Hypothesis B: If projects with government financing - irrespective of the terms - expire faster than their control groups of patents, then the failure is caused by the government choosing bad projects. 


\subsection{Patent citations}

Trajtenberg (1990) shows that forward citations are an indicator of the social value of a patent. The more frequently a patent is cited by later patents, the higher is the spillover effect and hence the social value of the cited patent. In the literature, forward citations have frequently been used as a measure on patent value, though it is often discussed whether forward citations really measure patent value and / or spillover effects (Hall et al., 2006). A patent can be cited any time after the application date, also after it has expired.

The data on patent citations are right censored if the end point of observation is fixed. A patent which has a later application date will on average be cited fewer times than a patent with an early application date. Therefore, the citations in the present study are weighted by the number of days from the application date until October 2007. To get an easier interpretation, the citation variables are then multiplied by 1826 (the number of days in a 5 year period). The citation variables will the measure how many citations the patents receive during a five year period.

CIT measures the total number of citations a patent and its patent equivalents have received during a five year period. ${ }^{23}$ Self-citations are excluded. This kind of forward citation variable has in the literature been regarded as a indicator of patent value and is expected to have a negative impact on the hazard. As discussed in section 2, I also divide this citation variable on intra-industry and inter-industry citations according to Maurseth (2005): INTRA shows the number of intra-industry forward citations, whereas INTER measures the number of inter-industry citations, based on the ISIC technology classes of the patents. ${ }^{24}$ According to Maurseth, a high value of INTRA shows that the patent faces hard competition from later patents. Therefore, INTRA should have a positive impact on the hazard that the patent expires. On the other hand, a high value of INTER is an indication of that the patent is a scientific breakthrough. Thus, a negative effect is expected on the hazard.

According to Hall et al. (2005), there are different procedures when patents are cited. At EPO, the European Patent Office, the patent examiners add references to

\footnotetext{
${ }^{23}$ A patent equivalent is the same patent granted at a different patent office, e.g. EPO, USPTO.

${ }^{24}$ The ISIC technology field classification is built on the eight digit level. In Espacenet, from where the classification has been collected, the classification is mostly only shown on a six digit level. In line with Maurseth, the citation is within the same technology class, if the cited and the citing patents have the same classification on the five digit level. If they have not the same five digit classification, then the citation is regarded as between technology classes. This division of citations on within and between classes can also be done on the four digit level, but the results of the estimations are similar.
} 
previous patents, meaning that the citations should be consistent. At USPTO, the U.S. Patent and Trade Office, the inventors / applicants themselves are required to add references to prior art. Thereafter, the patent examiners decide which patents should be cited. According to Michel and Bettels (2001) and Ejermo and Kander (2007), U.S patents have a higher requirement for citing other patents, implying that they cite more frequently than EPO- and PTC-patents. This suggests that U.S. citations are less valuable than citations from EPO and PTC. For this reason, forward citations from primarily EPO- and PTC patents are used to measure citations in the empirical analysis.

\subsection{Other control variables}

The included control variables might be correlated with the renewal scheme. Firms and individuals have different resources for renewing their patents, so I include additive dummies for different firm sizes. MEDIUM is a dummy that takes on the value of 1 for medium-sized firms with 101-1000 employees and 0 otherwise. SMALL equals 1 for small firms with 11-100 employees and 0 otherwise. Finally, MICRO is a third dummy variable taking the value of 1 for micro companies with 2-10 employees and 0 otherwise. The firm group dummies relate here to the reference group of the individual inventors.

The additive dummy $U N I V$ equals 1 for university patents and 0 otherwise. MOREPAT is an additive dummy, which equals 1 if the inventors or the applying firm have other competitive patents in the same technology area and 0 otherwise. The dummy COMPL takes on the value of 1 if complementary patents are needed for commercialization and 0 otherwise. The variable INVNMBR measures the number of inventors of the patent. Some characteristics of the inventors are also included in the mode. SEX measures the share of inventors (for each patent) who are female. ETH measures the share of inventors who belong to ethnic minorities, i.e. immigrants from other countries than Western Europe. OWNER measures how large a share (in percent) of the patent the inventors own directly or indirectly.

Different technologies are likely to be associated with different risks. Consequently, the type of technology can affect the conditional probability of a patent expiring. Patents are divided into 30 technology categories according to Breschi et al. (2004). These groups are based on the patents' main IPC-Class. ${ }^{25}$ The data is divided

\footnotetext{
${ }^{25}$ All technology categories are not represented in the dataset and some categories do not have enough observations. Therefore, only 26 categories and 25 additive dummies are used in the present study The
} 
into six different kinds of regions according to NUTEK (1998): Large-city regions, university regions, regions with important primary city centers, regions with secondary city centers, small regions with private employment, and small regions with government employment. Five additive dummies are included in the estimations for these six groups. Additive dummies are also included for different application years, to control for economic chocks that may affect all patents in a given year. The data has nine application years (1990-98) and eight additive dummies are assigned for these years. ${ }^{26}$

\section{Empirical estimations}

\subsection{Survival functions}

Figure 1 shows the survival and hazard functions for the whole sample of patents, as well as for those patents with and without government financing as estimated by the Life-table method (actuarial method). The patent application year is set to 0 . The survival function for the whole sample (dotted thick line) does not decline from the outset, since a patent cannot expire until it has been granted, but starts to fall after 3-4 years. The corresponding hazard function (dotted thin line) is the highest around 4-11 years after the application. ${ }^{27}$ Considering patents with and without government financing, the survival functions suggest that the gap in the hazard rates of these two categories increases over time. The hazard is higher for patents with government financing. Both a Log-rank test and a Wilcoxon test (see, e.g. Allison, 1995) show the difference between the two survival functions to be highly significant. The chi-square statistics are 26.05 and 24.91, respectively, significant at the 1 percent level for 1 d.f.

[Figure 1]

Since patents are not at risk of expiring until they have been granted, a more accurate estimation of the survival and hazard functions is shown in Figure 2. The starting year is set to either 1997 or 1998 depending on whether the grant date occurs before or after the renewal (application) date. ${ }^{28}$ Year 1 is the first possible year when the

technology classes without enough observations are instead merged with other closely related classes (Breschi et al., 2004).

${ }^{26}$ Note that only one patent was applied for in 1986, respectively, and no patents were applied for during the 1987-89 period. Therefore, 1986 and 1990 have been merged into one group.

${ }^{27}$ About ten years after the application year, the survival and hazard functions are less reliable, because patents renewed in 2004 are right-censored.

${ }^{28}$ Left-truncation is not possible when using the Life-table method and all patents were granted in 1998. 
patent can expire. In Figure 2, the survival functions are declining from the outset and decline more steeply for each year. The corresponding hazard functions have an increasing trend. ${ }^{29}$ Similar to the previous figure, there is an increasing gap between the survival functions for patents with and without government financing. This difference is significant at the $1 \%$-level for both the Log-rank test and the Wilcoxon test. The chisquare statistics are 23.19 and 20.89 , respectively, for 1 d.f. The hazard function is also the highest for patents with government financing.

It would have been interesting to estimate survival and hazard functions with respect to commercialization. Since this is a time-dependent variable, however, this is instead included in the Cox estimations.

[Figure 2]

\subsection{Cox proportional hazard estimations}

The results of the Cox estimations are shown in Tables 5 and 6 . In order to test for robustness, a number of different model specifications are estimated. Model $\mathrm{I}$ is the main model. It includes all financing variables and forward citations from PTC and EPO-patents. Three versions of Model I are estimated including: (a) region dummies, (b) technology dummies; and (c) region and technology dummies. Models II-V include both region and technology dummies. Model II distinguishes between intra- and intertechnology citations. Models III and IV are similar to Models I and II, but include forward citations from all patent offices. In Model $\mathrm{V}$, the financing variables are omitted, since these variables are strongly correlated with the commercialization decision (Svensson, 2007).

[Table 5]

One of the main variables in the model is the time-dependent commercialization variable, COM. As expected, the parameter is negative and highly significant. When commercialization starts, the hazard decreases by 45 percent (Model I-c). As expected, patents used for pure defensive purposes, $D E F$, also have a significantly negative impact. The hazard decreases by 76 percent for shadow patents as compared to other

\footnotetext{
${ }^{29}$ The survival and hazard functions are not so reliable for the seventh year, since there is no year 7 for those patents with a start year of 1998.
} 
non-commercialized patents (Model I-c). ${ }^{30}$ Thus, there is an even stronger impact than for commercialized patents. It should be borne in mind, however, that many more patents are commercialized than used as shadow patents in this dataset of patents owned by small firms and individuals.

Government financing in the R\&D-phase, GOVRD, has a strongly significant and positive impact on the conditional probability that patents expire. The hazard is 48 percent higher for patents with government financing in the R\&D-phase as compared to patents without such financing (Model I-c). The parameter of GOVRD is stable across the models. This result is in line with the theoretical argument that government financing with soft terms gives the owners no incentives to commercialize or keep their patents in force. One objection might be that this impact is different across firm sizes. When including an interaction dummy for firms, GOVRD*D in Model I-c, the positive impact on the hazard is only valid for patents owned by individuals. The hazard is then around 59 percent higher for individuals with government R\&D-financing than for individuals without such financing. The parameter estimate for firms (GOVRD + $\left.G O V R D^{*} D\right)$ is insignificant and almost zero. ${ }^{31}$ The other two financing variables, PRIVRD and OTHRD, have no significant impact on the renewal decision.

[Table 6]

Neither market-oriented government loans (GOVCOM) nor private venture capital (PRIVCOM) have a statistically significant effect. There is no indication that patents receiving these kinds of financing in the commercialization phase differ from other commercialized patents with respect to the renewal pattern.

In sum, only patents with soft government financing given in the R\&D-phase have a worse performance than the average, whereas patents with more market oriented loans perform as the average. This result suggests that it is the terms of the financing that lead to the bad performance of government financed projects rather than the

\footnotetext{
${ }^{30}$ SHADOW does not have a significant impact on the hazard in Model I, but here the parameter estimate shows the difference as compared to all other patents. In Models II-V, the parameter estimate shows difference as compared to other non-commercialized patents, since a patent cannot both be a shadowpatent and commercialized.

${ }^{31}$ Measuring the financial variables as percentages of the R\&D-costs instead of as dummies, give similar results. If the government financing increases by 1 percent as a share of the R\&D-costs, the Hazard increases by 0.7 percent that the patent expires. Also in this case, this relationship only holds for individuals and not for firms.
} 
government choosing to lend money to bad projects. In other words, Hypothesis A dominates Hypothesis B (see section 5.2).

Looking at patent citations, CIT is both significant in Models Ia-c when only citations from EPO and PTC-patents are used as well as in Model III when citations from all kind of patents are used. This supports the view in the previous literature that forward citations are an indication of patent value. But when dividing the forward citations on intra-technology (INTRA) and inter-technology (INTER) citations in Models II and IV, both of them fail to show any significance.

Among the other explanatory variables, the firm size dummies (MEDIUM, SMALL and MICRO) have negative and significant parameter estimates. If the patent is owned by a medium-sized, small or micro firm as compared to an individual, the hazard that the patent expires decreases by around 73, 49 and 34 percent, respectively (Model I-c). Firm size appears to be negatively correlated with the probability that a patent expires. However, only medium-sized firms (MEDIUM) and micro firms (MICRO) are significantly different from each other. Finally, ownership, OWNER, decreases the hazard that the patent expires.

An objection against the model specification would be that the decisions of renewal, commercialization and using the patent for defensive purposes are taken by the owner. Thus, the decision of commercialization or using the patent for defensive purposes would be endogenously determined by other factors in the model. However, there is not a simultaneous relationship between commercialization and renewal decisions. Commercialization clearly determines the renewal decision. The former decision is made before the latter, and the main reason why inventors patent their inventions at all is to protect a product in the market or deter competitors from using the invention (Griliches, 1990). Thus there is a causal relationship. Svensson (2007) shows, however, that the commercialization decision is correlated with other explanatory factors in the model, for example, the financing variables, the firm size variables and whether the owner has more similar patents (MOREPAT). But these relationships should be seen as correlations, rather than causations. It seems unlikely that the firm size is the reason why the patent was commercialized or not. In this case, there might be multicollinearity between the explanatory variables. I test for multicollinearity by alternatively excluding variables that were correlated with the commercialization decision in Svensson (2007). In Model V, the financing variables are excluded. The 
parameter estimates of $C O M$ and $D E F$ are not affected by these exclusions. On the basis of this, I conclude that multicollinearity is not a cause for concern. ${ }^{32}$

\section{Concluding remarks}

This study has empirically estimated how government financing influences the renewal of patents among individual inventors and small firms. The model assumes that more valuable patents are kept for longer periods. What sets this study apart from previous work is that the empirical analysis includes two different kinds of government financing: (1) soft government loans offered in the R\&D-phase; and (2) more marketoriented government loans in the commercialization phase. This makes it possible to evaluate how the specific terms of the government loans are related to patent renewal. Previous studies have used renewal data to estimate the distribution of market values of patents, but seldom related the renewal decision to explanatory factors.

By using survival models, it is shown that patents with soft government financing in the R\&D-phase have a significantly higher probability to expire than patents without such financing. The effect on the probability is non-negligible; soft government loans increase the hazard by 47 percent. By estimating separate effects for individual inventors and firms, the different risk level of the types of projects is taken into account. It turns out that the positive effect of soft government R\&D-financing on patent expiration is only significant for individual inventors. On the other hand, projects with more market-oriented government loans granted in the commercialization phase have the same performance as commercialized patents without such financing.

The two different kinds of government loans are not directly comparable to each other, since market-oriented loans can only be given to commercialized patents. However, the analysis in this study enables us to relating each financing alternative to comparable groups of patents. The results suggest that the poor performance of projects financed by the government in the R\&D-phase is caused by bad financing terms, rather than bad choices of projects.

A policy implication of this finding is that government institutions should make their financing and loans more market-oriented already in the R\&D-phase. Above all, the loans in the early phase should be granted to the firm, and not to the project. In this

\footnotetext{
${ }^{32}$ An alternative statistical procedure would be to estimate instruments for the commercialization variables using a survival function, and then insert these instruments in the main Cox equation. This, however, would imply an instrumental variable technique involving two survival functions. To the best of my knowledge, such a two step method does not yet exist.
} 
case, the borrower can then only avoid repayment if the firm goes bankruptcy. Hence, there are no incentives for borrowers to close down the project and use acquired knowledge in a new project. In addition loans should be repaid to the government, even if the project fails or the patent is never commercialized. This would deter opportunists with bad inventions from applying for government loans. Furthermore, the repayment should be connected to the profit of the commercialization, instead of the turnover. This would provide incentives to commercialize, even if the expected profit is low.

One objection against the aforementioned results would be that it is natural that public funded projects have a worse performance than those financed by private investors, since government agencies frequently choose among projects that have been turned down by private investors. However, recent economic research has shown that this kind of soft government loans are more attractive for inventors and small firms than financing from private venture capitalists and business angels (Kaivanto and Stoneman, 2006). Thus, it is not likely that government choose among inferior projects, which have been turned down by private investors.

\section{References}

Allison, P.D., 1995, Survival Analysis Using SAS - A Practical Guide, SAS Institute Inc., Cary, NC.

Bottazzi, L., M. Da Rin and T. Hellmann, 2004, 'The Changing Face of the European Venture Capital Industry: Facts and Analysis', Journal of Private Equity, Vol. 8(1).

Braunerhjelm, P., 1999, 'Venture capital, mångfald och tillväxt', (Venture Capital, Variety and Growth), Ekonomisk Debatt, Vol. 27(4), pp. 213-22.

Breschi, S., F. Lissoni and F. Malerba, 2004, 'The Empirical Assessment of Firms' Technological Coherence: Data and Methodology', in The Economics and Management of Technological Diversification, J. Cantwell, A. Gambardella and O. Granstrand (eds.), Routledge, London.

Cohen, W.M., R.R. Nelson and J.P. Walsh, 2000, 'Protecting their Intellectual Asserts: Appropriability Conditions and why U.S. Manufacturing Firms Patent (or not)', NBER Working Paper No. 7552, NBER, Cambridge, MA.

Cox, D.R., 1972, 'Regression Models and Life Tables', Journal of Royal Statistical Society, B34, pp. 187-220.

Duguet, E. and N. Iung, 1997, 'R\&D Investment, Patent Life and Patent Value', Working paper No. G 9705, Institut National de la Statistique et des Études Economiques, Malakoff Cedex. 
Ejermo, O., and Kander, A., 2007, 'Swedish Business Research Productivity Improvements against International Trends', CIRCLE Working paper No. 2007/7, CIRCLE, Lund

Gompers, P., and Lerner, J., 2001, 'The Venture Capital Revolution', Journal of Economic Perspective, No. 2, pp. 145-168.

Griliches, Z., 1990, 'Patent Statistics as Economic Indicators: A Survey', Journal of Economic Literature, Vol. 28, pp. 1661-1707.

Griliches, Z., B.H. Hall and A. Pakes, 1987, 'The Value of Patents as Indicators of Inventive Activity', in Dasqupta, P. and P. Stoneman (eds), Economic Policy and Technological Performance, Cambridge University Press, Cambridge.

Guellec, D. and van Pottelsberghe de la Potterie, B., 2003, 'The impact of public R\&D expenditure on business R\&D', Economics of Innovation and New Technology, Vol. 12(3), pp. 225-243.

Guellec, D. and van Pottelsberghe de la Potterie, B., 2004. From R\&D to productivity growth: do the institutional settings and the source of funds of R\&D matter? Oxford Bulletin of Economics and Statistics, Vol. 66(3), pp. 353-378.

Hall, B.H., 1993, 'The Stock Market Valuation of R\&D Investment During the 1980s', American Economic Review, Vol. 83, pp. 259-64.

Hall. B.H., Jaffe, A. and Trajtenberg, M., 2005, 'Market Value and Patent Citations', RAND Journal of Economics, Vol. 36, pp. 16-38.

Hall, B.H., G. Thoma and S. Torrisi, 2006, 'The Market Value of Patents and R\&D: Evidence from European firms', Working paper No. 186, University Luigi Bocconi, Milano.

Harhoff, D., F. Narin, F.M. Scherer and K. Vopel, 1999, 'Citation Frequency and the Value of Patented Citations', Review of Economics and Statistics, Vol. 81, pp. 511-15.

Hellmann, T. and M. Puri, 2002, 'Venture Capital and the Professionalization of StartUp Firms: Empirical Evidence', Journal of Finance, Vol. 57, pp. 169-97.

Jensen, R. and M. Thursby (2001), 'Proofs and Prototypes for Sale: The Licensing of University Inventions', American Economic Review, Vol. 91, pp. 240-59.

Kaivanto, K. and Stoneman, P., 2006, 'Public provision of Sales Contingent Claims backed finance on SMEs: A Policy Alternative', Research Policy, Vol. 36(5), pp. 63751 .

Kaplan S. N. and P. Strömberg, 2001, 'Venture Capitals as Principals: Contracting, Screening, and Monitoring', American Economic Review, Vol. 91, pp. 426-30.

Kirzner, I., 1985, 'Entrepreneurship and American competition', in: Butler, S.M., Dennis, W. (Eds.), Entrepreneurship: The Key to Economic Growth, Heritage 
Foundation and National Federation of Independent Business, Washington, D.C., pp. 17-22.

Kortum, S. and J. Lerner, 2000, 'Assessing the Contribution of Venture Capital to Innovation', RAND Journal of Economics, Vol. 31, pp. 674-92.

Lichtenberg, F.R., 1993, 'R\&D investment and international productivity differences', in: Siebert, H. (Ed.), Economic Growth in the World Economy, Mohr, Tubingen, pp. 89110.

Maggioni, V., Sorrentino, M. and Williams, M., 1999, 'Mixed consequences of government aid for new venture creation: evidence from Italy', Journal of Management and Governance, Vol. 3, pp. 287-305.

Maurseth, P.B., 2005, 'Lovely but Dangerous: The Impact of Patent Citations on Patent Renewal', Economics of Innovation and New Technology, Vol. 14, pp. 351-74.

Michels, J. and Bettels, B., 2001, 'Patent Citation Analysis. A Closer Look at the Basic Input Data from Patent Search Reports', Scientometrics, Vol. 51(1), pp. 185-201.

Morgan, R.P., Kruytbosch, C. and Kannankutty, N., 2001, 'Patenting and Invention Activity of U.S. Scientists and Engineers in the Academic Sector: Comparisons with Industry', Journal of Technology Transfer, Vol. 26, pp. 173-183.

Pakes, A., 1986, 'Patents as Options: Some Estimates of the Value of Holding European Patent Stocks', Econometrica, Vol. 54, pp. 755-84.

Rossman, J. and B.S. Sanders, 1957, 'The Patent Utilization Study', Patent, Trademark and Copyright Journal of Research and Education, Vol. 1, pp. 74-111.

Schankerman, M. and A. Pakes, 1986, 'Estimates of the Value of Patent Rights in European Countries during the Post-1950 Period', Economic Journal, Vol. 96, pp. 1052-76.

Schmookler, J., 1966, Invention and Economic Growth, Harvard University Press, Cambridge.

Svensson, R., 2007, 'Commercialization of Patents and External Financing during the R\&D-Phase', Research Policy, Vol. 36(7), pp. 1052-69.

Trajtenberg, M., 1990, 'A Penny for Your Quotes, Patent Citations and the Value of Innovations', RAND Journal of Economics, 21, pp. 172-187.

Van Pottelsberghe de la Potterie and B., Francois, D., 2006, 'The Cost Factor in Patent Systems', CEPR Discussion Paper No. 5944, CEPR, London. 


\section{Appendix: Soft loans provided by Swedish government authorities}

Among the Swedish government institutions, SIC (Foundation Innovation Centre) and NUTEK (Swedish Agency for Economic and Regional Growth) offered loans with soft terms to inventors and high-tech small firms from the beginning of the 1990s until 2005. The loans were given during the R\&D phase. SIC and NUTEK had a yearly budget of ca. 6-8 MUSD. The loans for individual projects could range from 10,000 to 150,000 USD.

To give soft loans to a firm or an inventor in the R\&D phase, the government authorities had three selection criteria: 1) the project should have a good chance of success both technically and commercially; 2) the project must be a high-tech project; and 3) the firm should not have more than 100 employees. Sometimes, the authorities also had a requirement that the project should generate a specific number of jobs. A difference between the institutions was that SIC loans were given to a higher degree to inventors and NUTEK loans to firms.

The government financing could cover up to 50-70 percent of the total R\&D costs depending on which government authority provided the loan. Thus, there was a requirement of co-financing by the borrower or somebody else. However this cofinancing was allowed to take the form of unpaid labor incomes. This is a cost which cannot be controlled by the government authority (moral hazard problems). Practically, the government loans could therefore cover more than 80 percent of the project's total $\mathrm{R} \& \mathrm{D}$ costs.

Three years after the loan was given, the borrower had to submit a report about the status of the project to the government authority. The repayment of the loan was connected to the turnover of the project and repayment possibly started after this report. If the project had failed, the loan was written off with a very high probability. If the project was based on a patent, then a requirement for write-off was that the patent was ended. There were some differences in the loan terms depending on whether the borrower had a firm or not when he or she signed the loan contract.

1) The borrower had already a firm and incomes from other projects. The interest rate was 4 percent above the base rate of the Bank of Sweden. Interest was paid every third month, but not until the final report date ( 3 years after contract). Repayment was 5 percent of turnover of the project, or 35 percent of royalties in the case of licensing.

2) The borrower had neither a firm nor incomes. The interest rate was $3.75 \%$ above the interest rate of the Bank of Sweden. Interest was paid from the first date and capitalized 
in the end of each year. Repayment was 7 percent of turnover of the project, or 35 percent of royalties in the case of licensing.

Practically, the borrower only needed to repay 50 percent of the loan if he had some incomes from the project when the report was submitted. SIC was wound up in 2003 and NUTEK in 2005, but similar loans have been offered by ALMI since 2003. The loan stocks of SIC and NUTEK were overtaken by ALMI. In 2005, ALMI evaluated the repayment of the loans offered by SIC and NUTEK. Only 13 percent of the SIC loans and 33 percent of the NUTEK loans had been repaid. Thus, the default rates of the soft loans were as high as 87 and 67 percent, respectively.

In the Netherlands similar soft loans have been given by TOK (Technisch Ontwikkelingskrediet). TOK had a default rate of 43 percent - considerably lower than in the Swedish case. The explanations are that the Dutch loans were also given to medium-sized firms and TOK had harder terms for co-financing and follow-up (Kaivanto and Stoneman, 2006). 
Figure 1. Survival and Hazard functions for the renewal of patents across financing alternatives.

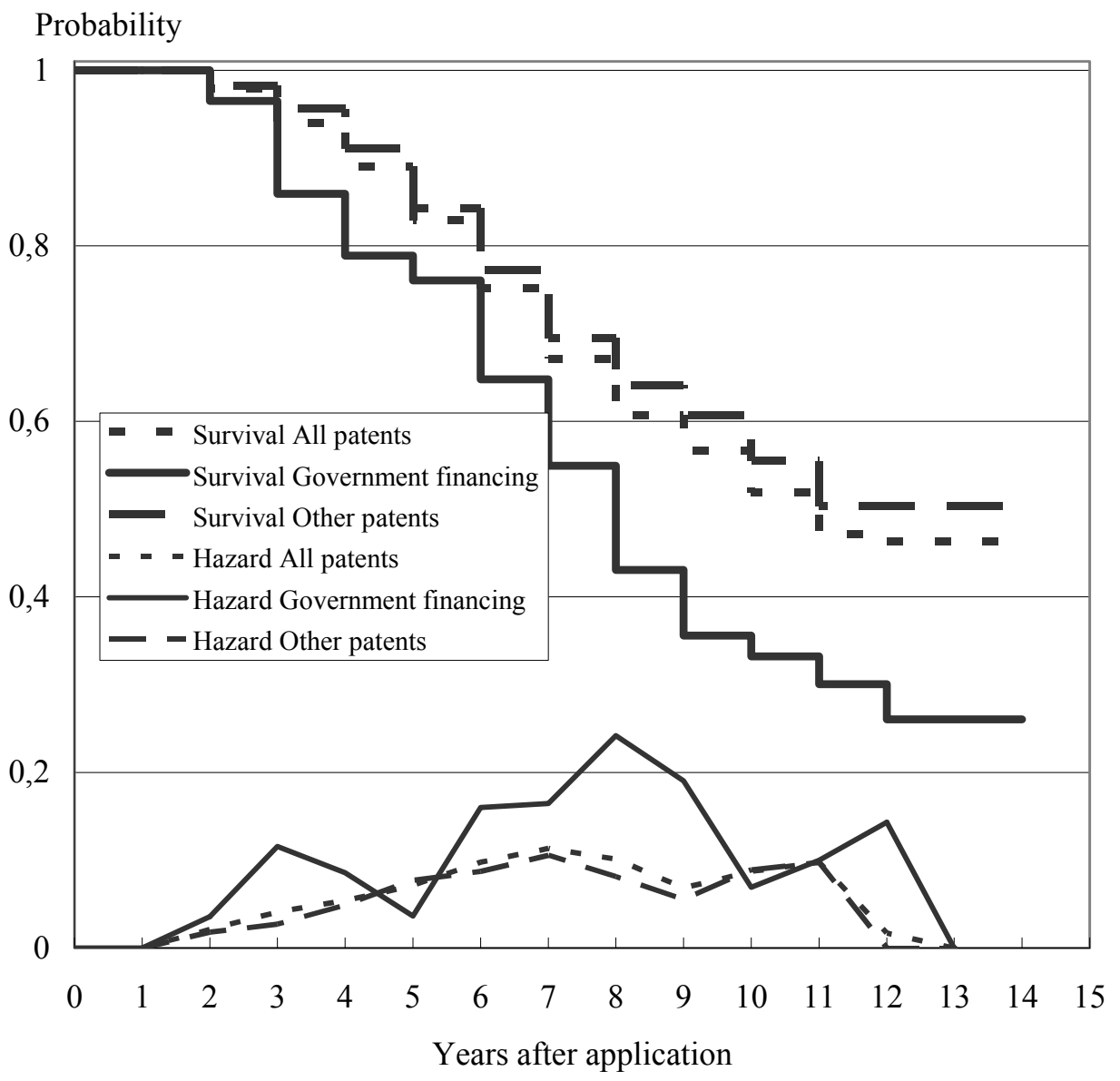


Figure 2. Survival and Hazard functions for the renewal of patents across financing alternatives

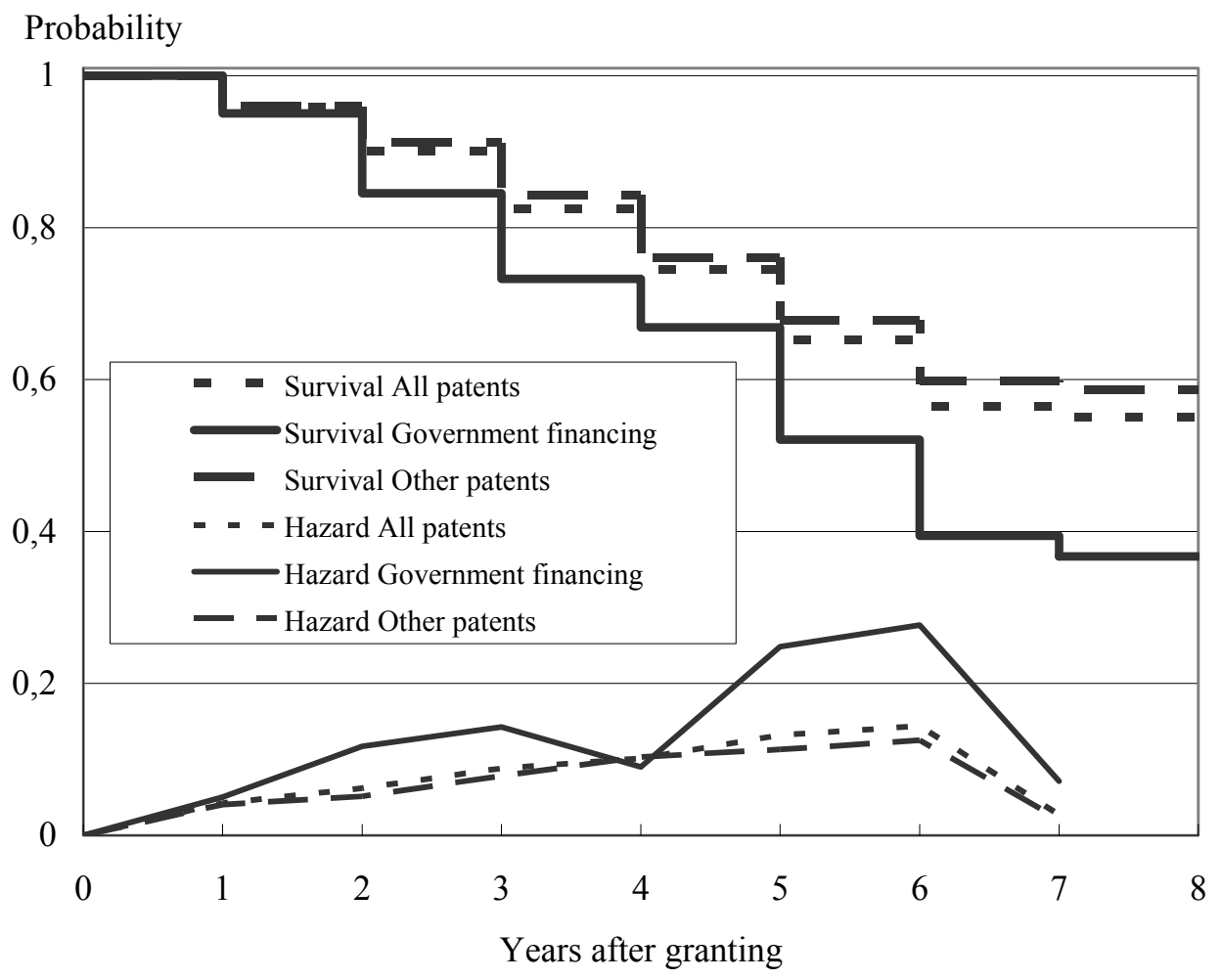


Table 1. Commercialization and renewal of patents across firm sizes, number of patents and percent.

\begin{tabular}{lccc}
\hline Kind of firm where invention was created & $\begin{array}{c}\text { Total number } \\
\text { of patents }\end{array}$ & $\begin{array}{c}\text { Percent } \\
\text { commercialized } \\
\text { latest 2003 }\end{array}$ & $\begin{array}{c}\text { Percent } \\
\text { renewed in } \\
2004\end{array}$ \\
\hline \hline Medium-sized firms (101-1000 employees) & 116 & $66 \%$ & $76 \%$ \\
\cline { 2 - 4 } $\begin{array}{l}\text { Small firms (11-100 employees) } \\
\text { Micro companies (2-10 employees) }\end{array}$ & 201 & $68 \%$ & $63 \%$ \\
\cline { 2 - 4 } Individuals (1-4 inventors) & 142 & $74 \%$ & $61 \%$ \\
\hline \hline Total & $\mathbf{8 6 7}$ & $\mathbf{6 1 \%}$ & $\mathbf{5 6 \%}$ \\
\hline
\end{tabular}

Table 2. External financing during the $R \& D$-phase and renewal of patents, number of patents and percent renewed.

\begin{tabular}{|c|c|c|c|c|}
\hline \multicolumn{5}{|c|}{ Any external financing } \\
\hline \multirow{2}{*}{$\begin{array}{l}\text { External financing } \\
\text { during the R\&D-phase }\end{array}$} & \multicolumn{2}{|c|}{ Renewal in 2004} & \multirow[t]{2}{*}{ Total } & \multirow[t]{2}{*}{ Percen } \\
\hline & Yes & No & & \\
\hline No & 390 & 270 & 660 & $58.7 \%$ \\
\hline Yes & 92 & 115 & 207 & $44.4 \%$ \\
\hline Total & 482 & 385 & 867 & $55.4 \%$ \\
\hline \multicolumn{5}{|c|}{ Chi-square $=13.64 * * *$} \\
\hline \multirow{2}{*}{$\begin{array}{l}\text { Government external } \\
\text { financing }\end{array}$} & \multicolumn{2}{|c|}{ Renewal in 2004} & \multirow[t]{2}{*}{ Total } & \multirow[t]{2}{*}{ Percent } \\
\hline & Yes & No & & \\
\hline No & 429 & 296 & 725 & $58.9 \%$ \\
\hline Yes & 53 & 89 & 142 & $37.3 \%$ \\
\hline Total & 482 & 385 & 867 & $55.4 \%$ \\
\hline \multicolumn{5}{|c|}{ Chi-square $=22.96 * * *$} \\
\hline \multirow[t]{2}{*}{ Private venture capital } & \multicolumn{2}{|c|}{ Renewal in 2004} & \multirow[t]{2}{*}{ Total } & \multirow[t]{2}{*}{ Percent } \\
\hline & Yes & No & & \\
\hline No & 459 & 360 & 819 & $55.8 \%$ \\
\hline Yes & 23 & 25 & 48 & $47.9 \%$ \\
\hline Total & 482 & 385 & 867 & $55.4 \%$ \\
\hline \multicolumn{5}{|c|}{ Chi-square $=1.21$} \\
\hline \multicolumn{5}{|c|}{ Other external financing (e.g., universities, research foundations) } \\
\hline \multirow[t]{2}{*}{ Other external financing } & \multicolumn{2}{|c|}{ Renewal in 2004} & \multirow[t]{2}{*}{ Total } & \multirow[t]{2}{*}{ Percent } \\
\hline & Yes & No & & \\
\hline No & 459 & 372 & 831 & $55.0 \%$ \\
\hline Yes & 23 & 13 & 36 & $63.9 \%$ \\
\hline Total & 482 & 385 & 867 & $55.4 \%$ \\
\hline \multicolumn{5}{|c|}{ Chi-square $=1.05$} \\
\hline
\end{tabular}

Note: 207 patents have external financing, but some patents have external financing from more than one source. 
Table 3. Commercialized patents and patents still alive 2004, number of patents and percent.

\begin{tabular}{lcccc}
\hline \multirow{2}{*}{ Patents still alive 2004 } & \multicolumn{2}{c}{ Commercialized patents latest in 2003 } & Tercent \\
\cline { 2 - 4 } & Yes & No & Total & $71 \%$ \\
Commercialized
\end{tabular}

Note: Chi-square-value is 44.32 , significant at the 1 percent level for $1 \mathrm{~d} . f$.

Table 4. Descriptive statistics and hypotheses for the explanatory variables.

\begin{tabular}{|c|c|c|c|c|}
\hline Denotation & Description & Mean & St.dev & $\begin{array}{c}\text { Expected impact } \\
\text { on hazard }\end{array}$ \\
\hline$C O M$ & $\begin{array}{l}\text { Time-dependent dummy that equals } 1 \text { when the } \\
\text { patent is commercialized and } 0 \text { otherwise. }\end{array}$ & 0.61 & 0.49 & - \\
\hline$D E F$ & $\begin{array}{l}\text { Dummy that equals } 1 \text { if the patent is a pure shadow } \\
\text { patent and } 0 \text { otherwise. }\end{array}$ & 0.02 & 0.13 & - \\
\hline GOVRD & $\begin{array}{l}\text { Dummy that equals } 1 \text { if part of R\&D was financed } \\
\text { by government and } 0 \text { otherwise. }\end{array}$ & 0.16 & 0.37 & + \\
\hline PRIVRD & $\begin{array}{l}\text { Dummy that equals } 1 \text { if part of R\&D was financed } \\
\text { by private venture capital and } 0 \text { otherwise. }\end{array}$ & 0.06 & 0.23 & - \\
\hline OTHRD & $\begin{array}{l}\text { Dummy that equals } 1 \text { if part of R\&D was financed } \\
\text { by universities/research foundations }\end{array}$ & 0.04 & 0.20 & + \\
\hline GOVCOM & $\begin{array}{l}\text { Interactive dummy taking the value of } 1 \text { if } \\
\text { commercialization was partly financed by } \\
\text { government and } 0 \text { otherwise. }\end{array}$ & 0.05 & 0.21 & $?$ \\
\hline PRIVCOM & $\begin{array}{l}\text { Interactive dummy taking the value of } 1 \text { if } \\
\text { commercialization was partly financed by private } \\
\text { venture capital and } 0 \text { otherwise. }\end{array}$ & 0.05 & 0.22 & \\
\hline$C I T$ & No. of forward citations during a five-tear period & 0.35 & 0.77 & - \\
\hline INTRA & $\begin{array}{l}\text { No. of forward citations within technologies during a } \\
\text { five-tear period }\end{array}$ & 0.30 & 0.70 & + \\
\hline INTER & $\begin{array}{l}\text { No. of forward citations between technologies } \\
\text { during a five-tear period }\end{array}$ & 0.05 & 0.16 & - \\
\hline MEDIUM & $\begin{array}{l}\text { Dummy taking the value of } 1 \text { for medium-sized } \\
\text { firms (101-1000 employees), and } 0 \text { otherwise. }\end{array}$ & 0.13 & 0.34 & \\
\hline$S M A L L$ & $\begin{array}{l}\text { Dummy taking the value of } 1 \text { for small firms (11- } \\
100 \text { employees), and } 0 \text { otherwise. }\end{array}$ & 0.23 & 0.42 & \\
\hline$M I C R O$ & $\begin{array}{l}\text { Dummy taking the value of } 1 \text { for micro companies } \\
\text { (2-10 employees), and } 0 \text { otherwise. }\end{array}$ & 0.16 & 0.37 & \\
\hline UNIV & $\begin{array}{l}\text { Dummy that equals } 1 \text { if the patent was created at a } \\
\text { university, and } 0 \text { otherwise. }\end{array}$ & 0.04 & 0.19 & \\
\hline MOREPAT & $\begin{array}{l}\text { Dummy taking the value of } 1 \text { if the inventors have } \\
\text { more similar (competitive) patents. }\end{array}$ & 0.41 & 0.49 & \\
\hline$C O M P L$ & $\begin{array}{l}\text { Dummy that equals } 1 \text { if complementary patents are } \\
\text { needed to create a product and } 0 \text { otherwise. }\end{array}$ & 0.23 & 0.42 & \\
\hline$I N V N M B R$ & Number of inventors of the patent. & 1.34 & 0.66 & \\
\hline OWNER & $\begin{array}{l}\text { Percent of the patent that is directly or indirectly } \\
\text { owned by the inventors. }\end{array}$ & 65.2 & 45.2 & \\
\hline$S E X$ & Share of inventors who are females & 0.02 & 0.14 & \\
\hline ETH & $\begin{array}{l}\text { Share of inventors with an ethnical background other } \\
\text { than Western European or North-American }\end{array}$ & 0.03 & 0.16 & \\
\hline
\end{tabular}


Table 5. Empirical estimations of the Cox model.

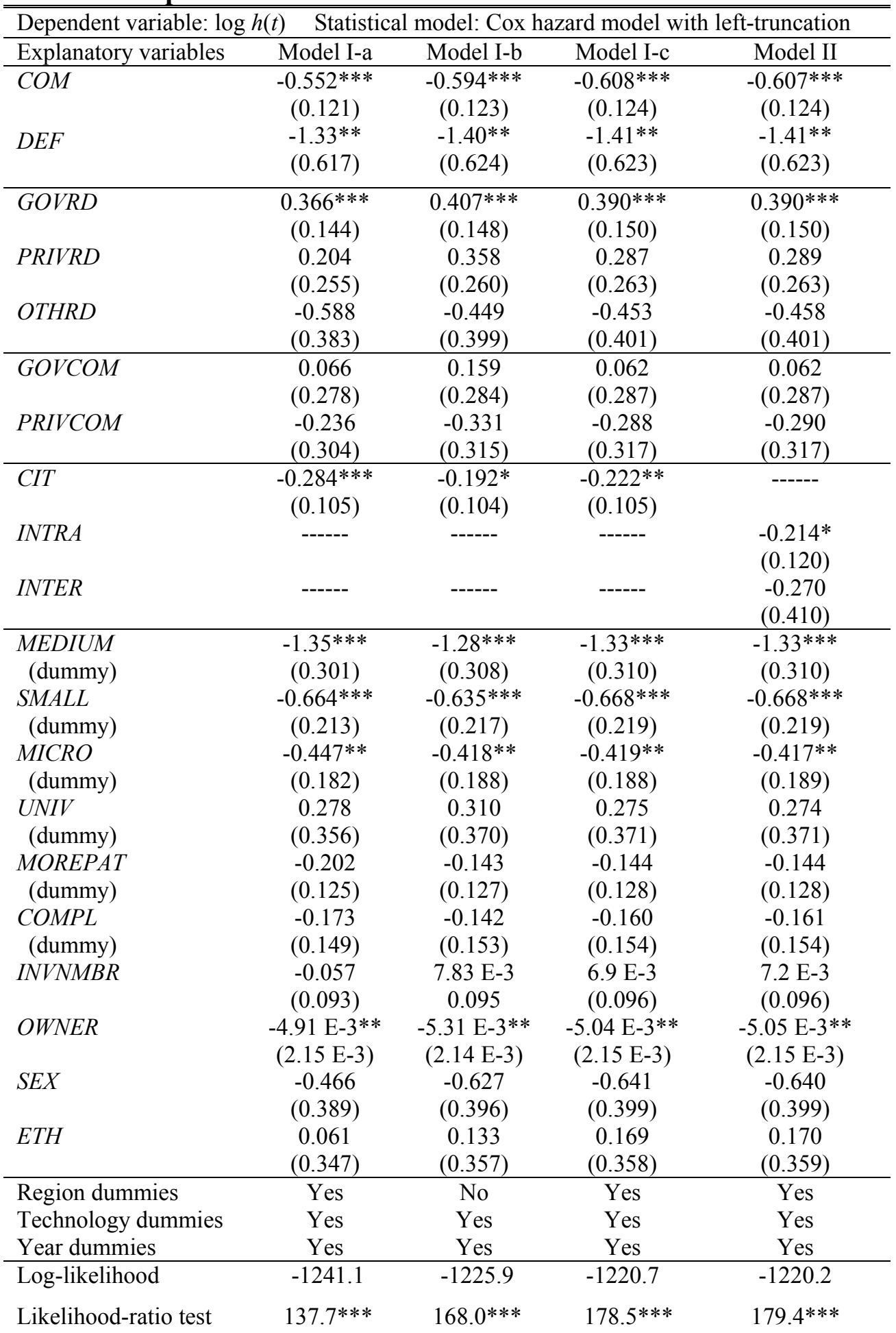

Note: The total number of observations equals 867,482 of which are right-censored. Standard errors are in parentheses and $* * *, * *$ and $*$ indicate significance at the 1,5 and 10 percent level, respectively. Region, technology and year dummies are not shown, but are available from the author upon request. 
Table 6. Robustness tests of the Cox model.

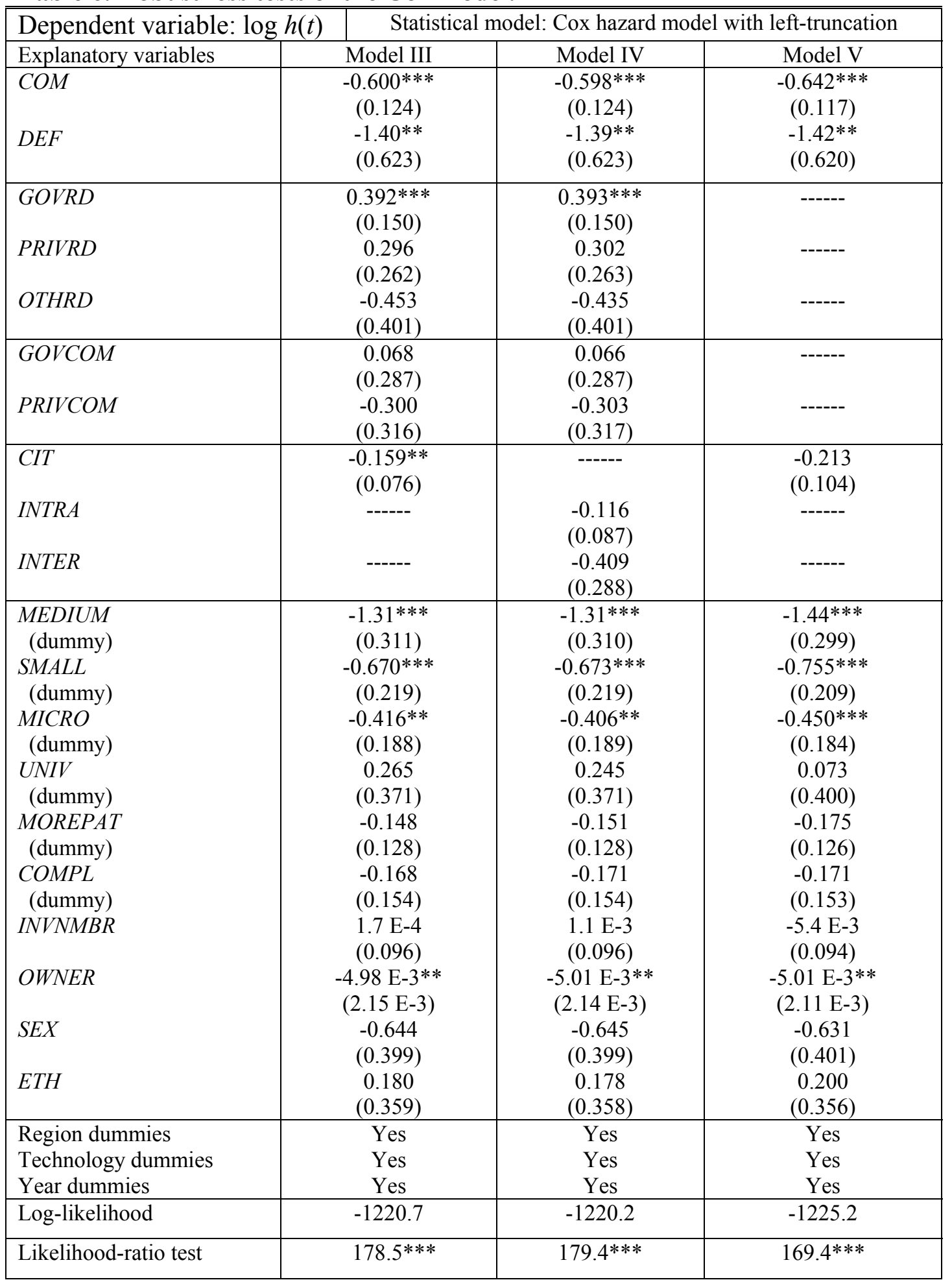

Note: The total number of observations equals 867,482 of which are right-censored. Standard errors are in parentheses and $* * *, * *$ and $*$ indicate significance at the 1,5 and 10 percent level, respectively. Region, technology and year dummies are not shown, but are available from the author upon request. 